Editorial

\title{
Double Blind Peer-Review in Religions
}

\author{
Martyn Rittman ${ }^{1}$ and Peter Iver Kaufman ${ }^{2}$
}

Received: 22 December 2015; Accepted: 22 December 2015; Published: 23 December 2015

1 MDPI AGKlybeckstrasse 64CH-4057 BaselSwitzerland; rittman@mdpi.com

2 Jepson School, University of Richmond, Room 133, Jepson Hall, 28 Westhampton Way, Richmond, VA 23173, USA; pkaufman@richmond.edu

Pre-publication peer-review forms the basis for how scholarly journals assess whether an article is suitable for publication. It is of paramount importance that the process is seen to be fair, robust and free of bias. One of the key methods for achieving these goals is blinding. Up until now, Religions has used single blind peer-review, where the reviewer identities are not known to authors. Journal editors take responsibility for the final acceptance decision, taking into account the reports provided by expert reviewers in the field.

In a single-blind process, authors may feel that they are not fairly treated. There is the suspicion that a renowned figure may be given an easy ride by reviewers, or that early career scholars are considered too inexperienced to assert their opinions.

We have decided to move Religions to a double blind peer-review process. For papers submitted after 31 December 2015, reviewers will not be informed of the author names of manuscripts until a final decision has been made. We believe that this policy will reduce bias and, in particular, help emerging scholars to receive a fair review. We are aware that no system is perfect, and some doubts have been raised about the extent to which double blind review solves the problem of reviewer bias. However, our aim is to demonstrate the commitment to scholarly endeavor at Religions.

We would like to take this opportunity to thank all the anonymous reviewers who contribute to the peer-review process. Their voluntary contributions, based on their experiences in the field help us to maintain a high standard in our published papers and underpins our editorial process.

Conflicts of Interest: The authors declare no conflict of interest.

(C) 2015 by the authors; licensee MDPI, Basel, Switzerland. This article is an open access article distributed under the terms and conditions of the Creative Commons by Attribution (CC-BY) license (http://creativecommons.org/licenses/by/4.0/). 